\title{
BMJ Open Potential clinical and economic impact of optimised maintenance therapy on discharged patients with COPD after hospitalisation for an exacerbation in China
}

Ahmed Salem, ${ }^{1}$ Heng Zhong, ${ }^{2}$ Mafalda Ramos, ${ }^{1}$ Mark Lamotte, ${ }^{1}$ Hao Hu (i) ${ }^{3}$

To cite: Salem A, Zhong $\mathrm{H}$, Ramos M, et al. Potential clinical and economic impact of optimised maintenance therapy on discharged patients with COPD after hospitalisation for an exacerbation in China. BMJ Open 2021;11:e043664. doi:10.1136/ bmjopen-2020-043664

- Prepublication history for this paper is available online. To view these files, please visit the journal online (http://dx.doi org/10.1136/bmjopen-2020043664).

AS and $\mathrm{HZ}$ contributed equally.

Received 10 August 2020

Revised 18 March 2021

Accepted 14 April 2021

Check for updates

(C) Author(s) (or their employer(s)) 2021. Re-use permitted under CC BY-NC. No commercial re-use. See rights and permissions. Published by BMJ.

${ }^{1}$ Real World Evidence, IQVIA, Zaventem, Belgium

${ }^{2}$ R\&D China, AstraZeneca R\&D, Shanghai, China

${ }^{3}$ Institute of Chinese Medical Sciences, University of Macau, Macau, China

Correspondence to

Professor Hao Hu;

haohu@um.edu.mo

\section{ABSTRACT}

Objectives Chronic obstructive pulmonary disease (COPD) exacerbations requiring hospitalisation are a considerable burden, both clinically and economically. Although long-acting maintenance therapy is recommended in both the GOLD (Global Initiative for Chronic Obstructive Lung Disease) and Chinese COPD guidelines, proper implementation is lacking. The objective of this study was to assess the clinical and economic impact of prescribing long-acting maintenance therapy to discharged patients with COPD after hospitalisation for an exacerbation in China by using an outcomes model.

Design This health economic analysis was conducted using a Markov cohort model from the Chinese healthcare payer perspective. Two health states (alive and dead) were modelled, and exacerbations were included as possible events.

Setting The target population was Chinese patients with COPD, $>40$ years of age, who were hospitalised for an exacerbation, with 1 year of follow-up. A recent COPD national prevalence study was referenced for population calculations.

Intervention A hypothetical future scenario, where 100\% of patients would receive long-acting maintenance therapy after hospitalisation for an exacerbation, was compared with the current scenario, in which only $38.5 \%$ of patients are receiving long-acting maintenance therapy after hospitalisation.

Outcome measures Number of exacerbations, deaths and medical costs were measured.

Results We estimated that there were approximately 4 million Chinese patients with COPD who were hospitalised annually due to an exacerbation. By prescribing long-acting maintenance therapy, our model predicted that 917360 exacerbations and 4034 deaths could be avoided, translating into cost savings of $¥ 3.5$ billion (US $\$ 0.5$ billion). Scenario analysis also showed that if the rate of exacerbations requiring hospitalisation was higher than our base case analysis, cost savings could reach up to $¥ 10.7$ billion (US $\$ 1.5$ billion).

Conclusion Administering long-acting maintenance therapy to more patients with COPD at hospital discharge could considerably reduce exacerbations and healthcare spending in China.
Strengths and limitations of this study

- This is the first and pragmatic health economic model for evaluating the clinical and economic impact of optimised long-acting maintenance therapy on discharged patients with chronic obstructive pulmonary disease (COPD) in China, which could be used to shape COPD reimbursement policy by local payer authorities.

- All outcome measures were based on up-to-date global/China COPD guidelines and the latest clinical data on prevalence and efficacy published in top peer-reviewed journals.

- The major limitation is that not all data indexes are specific to China, while all available published data involving Chinese populations have been referenced in this model.

- The time horizon of the model is only 1 year, given that extrapolating further would bring too much uncertainty.

- Cost of maintenance therapies was not included in this model and savings obtained through reducing exacerbations will be partly offset by increased spending on drugs. Future studies have to monitor the impact of the pharmaceutical budget to compare the investment in maintenance therapy with the savings obtained.

\section{BACKGROUND}

Chronic obstructive pulmonary disease (COPD) is a lung disease characterised and defined by limitation of expiratory airflow and associated symptoms, including dyspnoea, cough and sputum production. ${ }^{1}$ These result from several pathological processes including loss of lung elastic recoil, fibrosis and narrowing of small airways. ${ }^{1}$ Smoking and biomass fuel exposure are a leading cause of COPD due to the inflammatory response induced by smoke inhalation. ${ }^{1}$ Genetic predisposition also plays a role in COPD, as 
heterogeneity is observed with regard to susceptibility to smoke and other factors. ${ }^{2}$

COPD poses a considerable clinical and economic burden on healthcare systems worldwide. ${ }^{3}$ It has been reported that even patients with mild COPD experience a substantially compromised quality of life. ${ }^{4}$ Hospitalisation due to COPD represents more than $70 \%$ of all COPDrelated medical costs, making it the second most costly respiratory disease. ${ }^{5}$ COPD is considered twice as costly if productivity losses are taken into account because it may force both the patient and their caregiver to leave the workplace. ${ }^{6}$

A meta-analysis conducted in 2016 reported COPD prevalence in China as $9.9 \%$ for individuals who are $\geq 40$ years of age. ${ }^{7}$ However, a more recent study (2018) has reported a higher COPD prevalence $(13.6 \%)$ for the same age group. ${ }^{8}$ COPD is the fourth leading cause of death in China. ${ }^{9}$ Various publications have reported that the total expenditure per patient with COPD accounts for $40 \%$ of an average family's income, whereas $32.5 \%$ of the direct economic burden of COPD in China was driven by hospitalisation. ${ }^{1011}$

The China National Strategy for COPD Management encourages physicians in China to adopt the recommendations of the Global Initiative for Chronic Obstructive Lung Disease (GOLD). However, proper implementation of these guidelines is lacking. ${ }^{12}$ In this context, we expect that Chinese patients who are hospitalised for a COPD exacerbation are not receiving optimal COPD treatment as per the GOLD recommendations when leaving the hospital. ${ }^{12-14}$ For pharmacological treatment, the GOLD 2019 recommendations state that long-acting $\beta_{2}$-agonists (LABAs) and long-acting muscarinic antagonists (LAMAs) are more convenient and effective in maintaining symptom relief than short-acting therapies. ${ }^{1}$ However, short-acting treatments are frequently prescribed rather than long-acting maintenance therapy. ${ }^{12}$ Currently, only a small proportion of patients with COPD in China receive long-acting maintenance therapy. For Chinese patients with COPD, there is no evidence regarding the impact of prescribing long-acting maintenance therapy after a hospitalisation for an exacerbation on reducing future exacerbations and rehospitalisations, which hinders the promotion and implementation of the national strategy for COPD. Thus, this study aimed to present the findings of a model which evaluates an alternative health policy for COPD in China that could reduce the clinical and economic burden on both patients and payers. We hypothesise that if all patients with COPD who are hospitalised due to a severe exacerbation were treated with longacting maintenance therapy after hospital discharge, this would result in improvements in clinical and economic outcomes, compared with current clinical practice. It is expected that the findings from this study will improve clinical and policy decisions regarding COPD in China, and provide data for other countries that are also facing the rising challenges of this disease.
Compared Scenarios

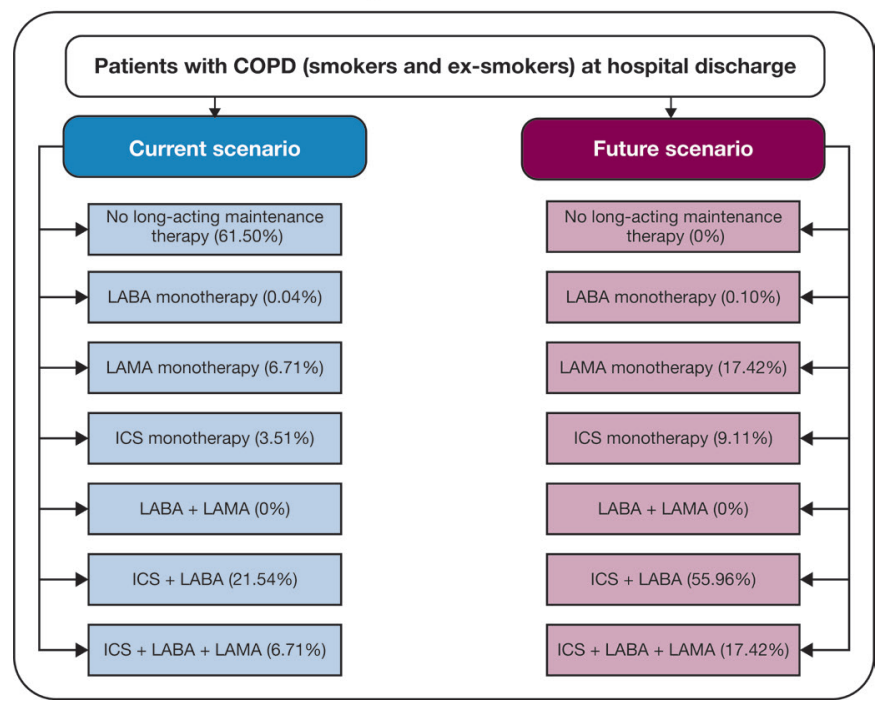

Figure 1 Compared scenarios. COPD, chronic obstructive pulmonary disease; ICS, inhaled corticosteroid; LABA, longacting $\beta_{2}$-agonist; LAMA, long-acting muscarinic antagonist.

\section{METHODS}

\section{Study design}

The current study examined the difference in health outcomes and costs for two treatment scenarios for patients with COPD in China: (1) a future (hypothetical) scenario in which all patients with COPD are treated with long-acting maintenance therapy after hospitalisation due to a severe exacerbation; and (2) a scenario representative of the current treatment paradigm, in which only some (ie, $38.50 \%$ ) of the patients with COPD are treated with long-acting maintenance therapy after hospital discharge. ${ }^{15}$

The possible long-acting maintenance treatments included in this analysis were LABA, LAMA, inhaled corticosteroids (ICS), LABA+LAMA combination, ICS+LABA combination, ICS+LABA+LAMA combination and the option of receiving no long-acting inhaled maintenance treatment (some of this population may receive theophylline and short-acting treatments). The study was a cost-outcome description study in which the outcomes and costs of the respective scenarios were assessed separately, as shown in the schematic diagram (figure 1). In this analysis, we presented outcome results as the number of deaths and avoided deaths, the number of exacerbations and avoided exacerbations, and finally the number of avoided hospitalisations. Cost results are shown as event costs and avoided healthcare costs between the two scenarios.

\section{Model structure}

Several methodologies can be used to develop a model in COPD. We opted to use the Markov technique. This has been the most applied modelling technique in COPD. ${ }^{16}$ Thus, the model was a simple Markov model with two health states (alive and dead) developed in Microsoft Excel (figure 2). The starting cohort consisted of patients 


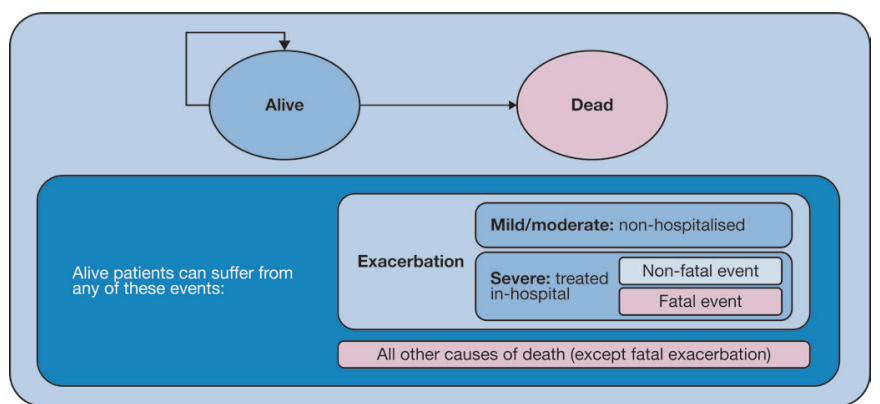

Figure 2 Health states.

with COPD who were discharged from hospital after a severe exacerbation. The model had a time horizon of 1 year and a cycle length of 1 month. Each month the patient had a risk of experiencing a moderate or severe exacerbation, where severe exacerbation is defined as one that required hospitalisation and could be fatal. Also, each month there was a possibility of dying due to other causes.

\section{Target population}

As mentioned above, the target population consisted of patients with COPD discharged from hospital after a severe exacerbation. To estimate the size of this population, a stepwise approach was followed. First, we calculated the number of patients in the population, based on the prevalence of COPD in China in people $>40$ years of age (13.6\%). ${ }^{817}$ Among these, we applied an estimated proportion of patients who had a history of admission to hospital for COPD (50.84\%) over the previous year. ${ }^{8}$ Based on this, we estimated that 4078838 patients in China are hospitalised annually for COPD exacerbations.

Regarding the exacerbation rates, international published literature was sought to provide an estimate as, to the best of our knowledge, there are no data specific to China on COPD exacerbation risks. We conducted a pragmatic literature search to identify the best available evidence on the impact of long-acting maintenance therapies on COPD exacerbation rates. Our search criteria targeted publications in which outcomes included exacerbation rates for patients who had a history of $\geq 1$ exacerbation, in addition to publications that included all the drug classes accounted for in the current analysis. A total of 14 publications were identified, but only 2 were considered to fit our model concept. ${ }^{18-31}$ The two publications were by Mills $e t a l^{28}$ and Pavord $e t a l^{22}$ The publication by Mills $e t a t^{28}$ reported the annual number of exacerbations per year without long-acting maintenance treatment (1.21) and the associated relative risks of all maintenance treatments compared with placebo. The exacerbation rate without long-acting maintenance treatment was converted into a monthly exacerbation rate $(0.1019)$ to fit the 1-month cycle length.

We also looked at recent publications which reported the relative risk of LABA+LAMA and ICS+LABA+LAMA compared with ICS+LABA. ${ }^{32}{ }^{33}$ For the LABA+LAMA combination, the reported HR $(0.86 ; 95 \%$ CI 0.76 to
0.99) was used to calculate the relative risk of exacerbation compared with ICS+LABA. ${ }^{32}$ For ICS+LABA+LAMA triple therapy, Calzetta $e t a \hat{l}^{3}$ reported the relative risk of (fixed) ICS+LABA+LAMA versus fixed ICS+LABA, which was 0.78 (95\% CI 0.71 to 0.85$).{ }^{33}$ We applied these relative risks to compute the relative risk of exacerbation with the combination of LABA+LAMAand triple therapy with ICS+LABA+LAMA, respectively. The proportion of exacerbations requiring hospitalisation (ie, severe exacerbation) for non-treated and treated patients was also derived from the literature (non-treated $=16.8 \%$; treated $=17.8 \%){ }^{22}$

The defined target population for this analysis included both smokers and former/non-smokers with COPD in China. Because smokers have a higher risk of exacerbations compared with former/non-smokers, a distinct incidence rate of exacerbation was applied to each subpopulation. The proportion of smokers was informed by the results from a published cross-sectional survey of a nationally representative sample of individuals from mainland China $\geq 40$ years of age. ${ }^{8}$ In this sample, $31.4 \%$ of individuals were reported to be current smokers. An HR for former/non-smokers (0.84) compared with current smokers was computed, which allowed for a different incident rate of exacerbations for the two subpopulations. ${ }^{34}$ The exacerbation rate for patients not receiving long-acting maintenance treatment (0.1019) could then be deconstructed into a distinct exacerbation rate for former/non-smokers and smokers (formula 1 ) where the exacerbation rate for former/non-smokers was calculated separately (formula 2):

- Formula 1: exacerbation rate for smokers $\times$ proportion of smokers + exacerbation rate for non-smokers $\times$ proportion of non-smokers $=0.1019$.

- Formula 2: exacerbation rate for smokers $\times$ HR for non-smokers (0.84).

Thus, the imputed exacerbation rate was 0.1145 for smokers and 0.0962 for non-smokers.

All model inputs are listed in table 1.

\section{Treatment paradigm}

The distribution of patients per treatment option in both scenarios reflected the current and future (potential) scenarios. For the current scenario, we used the Chinese Health Insurance Database to extract the percentage of patients receiving each treatment option in $2015 .{ }^{15} \mathrm{In}$ 2015, only $38.5 \%$ of all patients with COPD in China were treated with long-term maintenance therapy. The proportion of patients receiving each long-acting maintenance treatment in the current scenario is shown in table 1.

In the future scenario, it was assumed that $100 \%$ of patients would receive long-acting maintenance treatment after discharge from the hospital due to a COPD exacerbation. As we had no information on what the preferred treatments would be, we redistributed patients to the different long-acting maintenance treatments. Note that theophylline, often used in China, was considered as background therapy in both scenarios. 
Table 1 Summary of inputs

\begin{tabular}{|c|c|c|}
\hline Base case & $\begin{array}{l}\text { Value used } \\
\text { in model }\end{array}$ & Source \\
\hline $\begin{array}{l}\text { Population in China }>40 \text { years of } \\
\text { age, } n\end{array}$ & 999715200 & 7 \\
\hline $\begin{array}{l}\text { Prevalence of COPD in the } \\
\text { Chinese population }>40 \text { years of } \\
\text { age, } \%\end{array}$ & 13.6 & 8 \\
\hline $\begin{array}{l}\text { Proportion of patients with } \\
\text { exacerbations, \% }\end{array}$ & 5.9 & 8 \\
\hline $\begin{array}{l}\text { Patients experiencing COPD } \\
\text { exacerbations, } n\end{array}$ & 8021715 & Calculated \\
\hline $\begin{array}{l}\text { Incidence of hospitalisation due } \\
\text { to exacerbations per patient with } \\
\text { COPD, \% }\end{array}$ & 50.8 & 8 \\
\hline $\begin{array}{l}\text { Total number of hospitalised } \\
\text { patients with COPD, } n\end{array}$ & 4078838 & Calculated \\
\hline Smokers in China, \% & 31.4 & 8 \\
\hline $\begin{array}{l}\text { HR of exacerbations (ex-smokers } \\
\text { vs smokers) }\end{array}$ & 0.84 & 33 \\
\hline \multicolumn{3}{|c|}{ Patients per treatment: current scenario, \% } \\
\hline LABA alone & 0.04 & 15 \\
\hline LAMA alone & 6.71 & 15 \\
\hline ICS alone & 3.51 & 15 \\
\hline LABA+LAMA & 0.00 & 15 \\
\hline ICS+LABA & 21.54 & 15 \\
\hline ICS+LABA+LAMA & 6.71 & 15 \\
\hline $\begin{array}{l}\text { No long-acting inhaled } \\
\text { treatment }\end{array}$ & 61.50 & 15 \\
\hline
\end{tabular}

Patients per treatment: future scenario, \%

\begin{tabular}{|lll}
\hline LABA alone & 0.10 & Assumed \\
\hline LAMA alone & 17.42 & Assumed \\
\hline ICS alone & 9.11 & Assumed \\
\hline LABA+LAMA & 0.00 & Assumed \\
\hline ICS+LABA & 55.96 & Assumed \\
\hline ICS+LABA+LAMA & 17.42 & Assumed \\
\hline No inhaled treatment & 0.00 & Assumed \\
\hline Rate of exacerbations per patient-month & \\
\hline $\begin{array}{l}\text { Placebo (reference), \% } \\
\text { Risk reduction compared with } \\
\text { placebo }\end{array}$ & 10.19 & 27 \\
\hline $\begin{array}{l}\text { LABA alone } \\
\text { LAMA alone }\end{array}$ & \\
\hline ICS alone & 0.83 & 27 \\
\hline LABA+LAMA & 0.74 & 27 \\
\hline ICS+LABA & 0.79 & 27 \\
\hline ICS+LABA+LAMA & 0.59 & 31 \\
\hline Proportion of exacerbations requiring hospitalisations, \% \\
\hline $\begin{array}{l}\text { No inhaled controller treatment } \\
\text { at discharge }\end{array}$ & 16.8 & 21 \\
\hline
\end{tabular}

Continued
Table 1 Continued

\begin{tabular}{lll}
\hline Base case & $\begin{array}{l}\text { Value used } \\
\text { in model }\end{array}$ & Source \\
\hline $\begin{array}{l}\text { Inhaled controller treatment at } \\
\text { discharge }\end{array}$ & 17.8 & 21 \\
$\begin{array}{l}\text { Mortality } \\
\begin{array}{l}\text { Monthly risk of death after a } \\
\text { first hospitalisation }\end{array}\end{array}$ & 0.011 & 29 \\
$\begin{array}{l}\text { Risk of fatal rehospitalisation } \\
\text { Costs of events (¥) }\end{array}$ & 0.034 & 35 \\
$\begin{array}{l}\text { Moderate exacerbation } \\
\text { (outpatient visit) }\end{array}$ & 319 & 36 \\
$\begin{array}{l}\text { Severe exacerbation/ } \\
\text { rehospitalisation }\end{array}$ & 24373 & 37 \\
\hline \begin{tabular}{l} 
Fatal severe exacerbation \\
\hline
\end{tabular} & 24373 & Assumed \\
\hline
\end{tabular}

COPD, chronic obstructive pulmonary disease; ICS, inhaled corticosteroids; LABA, long-acting $\beta_{2}$-agonist; LAMA, long-acting muscarinic antagonist.

\section{Mortality}

Patients with COPD may die due to a fatal severe exacerbation or other causes. Soler-Cataluña $e t a l^{30}$ showed that patients with more hospital readmissions due to a COPD exacerbation are at a higher risk of non-COPD-related death than patients who previously suffered fewer acute exacerbations. We computed the cumulative mortality at 12 months (0.1194) and converted this to a monthly risk of death $(0.0105)$ using the formula by Miller and $\operatorname{Homan}^{35}$ :

$$
P_{j}=1-\left[1-P^{1 / t}\right]
$$

where $P_{j}$ is the monthly transition risk, $t=12$, and $P$ represents the cumulative mortality of 12 months.

Also, a COPD exacerbation case fatality of $3.4 \%$ was applied to severe exacerbations. ${ }^{36}$

\section{Costs}

Events in the model were divided into moderate and severe. For moderate exacerbations, an outpatient visit cost was applied using results from published literature and adjusted for 2017 Chinese yuan (US dollar) values. ${ }^{37}$ The literature reported that an outpatient visit in China costs $¥ 319$ (US\$46).$^{37}$ For severe exacerbations, we adopted the average cost of hospitalisation as $¥ 24373$ (US\$3544), sourced from a recent retrospective analysis based on medical record data from the First Affiliated Hospital of Guangzhou Medical University. ${ }^{38}$ We assumed that the cost of a fatal exacerbation was the same as that for a severe exacerbation. The basis of this assumption is that a patient with COPD who has a fatal exacerbation will first experience a severe exacerbation requiring hospitalisation, which in turn can be fatal. 


\begin{tabular}{|c|c|c|c|}
\hline & $\begin{array}{l}\text { Current } \\
\text { scenario }\end{array}$ & $\begin{array}{l}\text { Future } \\
\text { scenario }\end{array}$ & $\begin{array}{l}\text { Estimated } \\
\text { reductions }\end{array}$ \\
\hline $\begin{array}{l}\text { Proportion/risk } \\
\text { of patients dying, } \\
\%\end{array}$ & 12.45 & 12.35 & -0.10 \\
\hline $\begin{array}{l}\text { Number of } \\
\text { deaths, } n\end{array}$ & 507705 & 503672 & -4034 \\
\hline $\begin{array}{l}\text { Number of } \\
\text { exacerbations, } n\end{array}$ & 4070088 & 3152728 & -917360 \\
\hline $\begin{array}{l}\text { Number of } \\
\text { hospitalisations, } \\
n\end{array}$ & 696538 & 561759 & -134779 \\
\hline $\begin{array}{l}\text { Healthcare costs } \\
(¥)\end{array}$ & 18052707442 & 14518128038 & -3534579404 \\
\hline
\end{tabular}

\section{Time horizon and discount rate}

The model had a time horizon of 1 year, which was deemed appropriate because the purpose of this study was to show the immediate impact of changing treatment behaviour for the Chinese healthcare payer. Given this 1 -year time horizon, discounting of $0 \%$ was applied in the model to both costs and effects. ${ }^{39}$ This means that there is no need to adjust the costs or health outcomes for net present value because they fall within a 1-year time frame (ie, not future costs or health outcomes).

\section{Patient and public involvement}

There was no patient or public involvement in this study.

\section{RESULTS}

\section{Base case results}

By applying the settings described above to the model and using an estimated number of approximately 4 million Chinese patients with COPD, we calculated that approximately 0.9 million exacerbations, 134779 rehospitalisations for exacerbations and 4034 deaths due to an exacerbation could be avoided by administering longacting maintenance therapy to patients with COPD after discharge from hospital after an exacerbation (table 2). The resulting savings in healthcare costs are expected to be ¥3.5 billion (US $\$ 0.51$ billion).

\section{Scenario analysis}

We modelled different scenarios to assess the robustness of the results after altering key assumptions (table 3). In the first scenario, we used a much lower prevalence of COPD in China $(3.6 \%)$ as per an available publication, which hence reduced the starting target population from the base case of 4 million to 2.3 million. ${ }^{40}$ Despite the smaller population size, the model still determined that many exacerbations and hospitalisations could be avoided and that savings in healthcare costs remained considerable (¥1.9 billion (US $\$ 0.28$ billion); table 3 ).

We also tested a scenario in which the proportion of exacerbations requiring rehospitalisation was $48 \%$, as per other publications, instead of the base case $(16.8 \%){ }^{41}$
Results showed that approximately 0.5 million hospitalisations could be avoided, with a reduction in related healthcare costs of around $¥ 10$ billion (US $\$ 1.45$ billion).

Furthermore, we tested two scenarios where a proportion of patients on 'no treatment' in the current scenario did not shift to a treatment in the future scenario. The first scenario assessed the cost savings when only $20 \%$ of the patients currently on 'no treatment' received a treatment in the future scenario (table 3). The cost savings were $¥ 0.7$ billion (US $\$ 0.1$ billion) with 26956 hospitalisations avoided. The second scenario tested the cost savings when $50 \%$ of patients currently on 'no treatment' received a maintenance treatment in the future scenario (table 3). The cost savings under this scenario were $¥ 1.7$ billion (US $\$ 0.25$ billion) with 67390 avoided hospitalisations.

Finally, under the base case analysis, there were no patients treated with a LABA+LAMA combination, according to data from the China Health Insurance Database. So in our future scenarios, the use of LABA+LAMA continued to be non-existent. ${ }^{15}$ However, there have been recent launches of LABA+LAMA combinations, but no data are yet available on the market shares of these medications. ${ }^{42-44}$ Hence, we conducted a scenario where the percentage of patients receiving LABA+LAMA in the future scenario would be $5 \%$, as a conservative approach. Under this scenario, ¥3.6 billion (US $\$ 0.52$ billion) could be saved in healthcare costs, and 138429 hospitalisations and 4143 deaths could be avoided (table 3).

\section{DISCUSSION}

In the current analysis, we observed that optimising the posthospitalisation treatment for patients with exacerbations of COPD to include a long-acting maintenance therapy can have a positive impact on both clinical and economic outcomes in China. Our model demonstrated that 134779 hospitalisations could be avoided, translating into healthcare cost savings of ¥3.5 billion (US $\$ 0.51$ billion). Avoiding hospitalisations is a priority for the Chinese healthcare system, in which hospital beds for patients with COPD are a scarce resource. ${ }^{45}$ Our results indicate that adjusting the treatment strategy could help prevent rehospitalisations.

A major driver of this analysis was the relative proportion of all exacerbations that were hospitalised; this was expected since previous literature has reported that hospitalisations account for $32.5 \%-70 \%$ of all COPDrelated medical costs. ${ }^{511}$ Recent health economic studies reported a much higher proportion of hospitalised exacerbations than the percentage we used in the base case analysis. ${ }^{41}{ }^{46}$ Through our scenario analysis, adjusting for a higher percentage of hospitalisations, we observed that the number of avoided exacerbations and hospitalisations was maximised, leading to better net clinical outcomes and more considerable cost savings. Moreover, this study only took an average standard tariff for treatment of a COPD exacerbation in hospital. Because severe exacerbations/deteriorating patients may be transferred to 
Table 3 Scenario analyses

\begin{tabular}{|c|c|c|c|}
\hline & Current scenario & Future scenario & Estimated reductions \\
\hline \multicolumn{4}{|l|}{ Adjusted target population } \\
\hline Proportion/risk of patients dying, \% & 12.45 & 12.35 & -0.10 \\
\hline Number of deaths, $n$ & 286502 & 284226 & -2276 \\
\hline Number of exacerbations, $n$ & 2296784 & 1779111 & -517674 \\
\hline Number of hospitalisations, $\mathrm{n}$ & 393062 & 317005 & -76057 \\
\hline Healthcare costs $(¥)$ & 10187292121 & 8192699729 & -1994592392 \\
\hline \multicolumn{4}{|l|}{ Adjusted hospitalisation rate } \\
\hline Proportion/risk of patients dying, $\%$ & 13.36 & 13.04 & -0.32 \\
\hline Number of deaths, $n$ & 545035 & 531980 & -13055 \\
\hline Number of exacerbations, $n$ & 4048522 & 3140386 & -908136 \\
\hline Number of hospitalisations, $n$ & 1943291 & 1507385 & -435905 \\
\hline Healthcare costs $(¥)$ & 48034909136 & 37260054536 & -10774854600 \\
\hline \multicolumn{4}{|c|}{ 'No treatment' proportion displaced in future scenario=20\% } \\
\hline Proportion/risk of patients dying, \% & 12.45 & 12.43 & -0.02 \\
\hline Number of deaths, $n$ & 507705 & 506899 & -807 \\
\hline Number of exacerbations, $\mathrm{n}$ & 4070088 & 3886616 & -183472 \\
\hline Number of hospitalisations, $\mathrm{n}$ & 696538 & 669582 & -26956 \\
\hline Healthcare costs $(¥)$ & 18052707442 & 17345791561 & -706915881 \\
\hline \multicolumn{4}{|c|}{ 'No treatment' proportion displaced in future scenario $=50 \%$} \\
\hline Proportion/risk of patients dying, $\%$ & 12.45 & 12.40 & -0.05 \\
\hline Number of deaths, $n$ & 507705 & 505689 & -2017 \\
\hline Number of exacerbations, $\mathrm{n}$ & 4070088 & 3611408 & -458680 \\
\hline Number of hospitalisations, $\mathrm{n}$ & 696538 & 629148 & -67390 \\
\hline Healthcare costs $(¥)$ & 18052707442 & 16285417740 & -1767289702 \\
\hline \multicolumn{4}{|l|}{$5 \%$ LABA+LAMA future scenario } \\
\hline Proportion/risk of patients dying, \% & 12.45 & 12.35 & -0.10 \\
\hline Number of deaths, $n$ & 507705 & 503562 & -4143 \\
\hline Number of exacerbations, $n$ & 4070088 & 3132245 & -937843 \\
\hline Number of hospitalisations, $\mathrm{n}$ & 696538 & 558109 & -138429 \\
\hline Healthcare costs $(¥)$ & 18052707442 & 14423805049 & -3628902393 \\
\hline
\end{tabular}

LABA, long-acting $\beta_{2}$-agonist; LAMA, long-acting muscarinic antagonist.

respiratory high dependency units for non-invasive ventilation, the cost saving from this study may be underestimated. Therefore, if more patients with COPD received long-acting maintenance therapy after discharge from hospital, this could lead to better health outcomes and reduced medical costs over time.

Our hypothesis aligns with the GOLD recommendations for COPD (2019) and is further substantiated by the results of this analysis. ${ }^{1}$ In addition, it is worth noting that our analysis considered only direct medical costs, and if indirect costs were taken into account the cost savings would likely increase. As described in previous literature, COPD is a disease that poses a challenge not only to the patient but also to their caregivers. ${ }^{5}$

To our knowledge, this is the first modelling study focusing on the clinical and economic impact of optimised posthospitalisation management for an exacerbation in patients with COPD in China. Our findings have several important implications. For clinicians in China, the findings imply that further efforts are needed to better adhere to the GOLD recommendations for posthospitalisation management of COPD exacerbations. For policymakers in China, it is suggested that a COPD prescription monitoring programme and reimbursement policy supporting long-acting maintenance after hospitalisation for exacerbation should be designed and implemented. For international management of COPD, our findings contribute by showing financial and health benefits from the use of long-acting maintenance therapies after hospital discharge, which is valuable for other countries that are facing the challenges of the rising prevalence of COPD and poor pharmacological management. 
Finally, we would like to emphasise that besides the pharmacological management for COPD, the importance of other health interventions cannot be neglected, particularly smoking cessation among active smokers and postdischarge pulmonary rehabilitation. Positive effects of smoking cessation and postdischarge pulmonary rehabilitation on reducing COPD exacerbation have been well reported in literature. ${ }^{47-49}$ Therefore, these health interventions need to be applied with pharmacological management to avoid further COPD exacerbation.

We note several limitations to this analysis, which should be addressed in future studies. First, some of the data used are not specific to China, including the key driver-the risk of hospitalisation for an exacerbation. However, during the conduct of the pragmatic literature search, which included both English and Chinese language publications, we found that available data on COPD in China were limited. Second, there was no consensus in the literature as to the proportion of COPD exacerbations that require rehospitalisation; therefore, we based our analysis on results from the TORCH study $(16.8 \%-17.8 \%)$, whereas other publications have reported percentage ranges as high as $48 \%-62.5 \% .^{22} 4146$ This variable is a crucial element in computing the results, and we took a conservative approach by opting for the lower value. Third, this model did not include the cost of maintenance therapies; with new medicine launches, the current prices of inhaler therapies would be expected to change. Our study aimed to look only at public health impact; therefore, the savings obtained through reducing exacerbations will be partly offset by increased spending on drugs, which should be considered for further models. Also, a time horizon of only 1 year was considered. However, extrapolating assumptions would result in a greater amount of uncertainty. Fourth, as the purpose of this study was to develop a simple and easy-to-understand model, we ran analyses based on point estimates and did some scenarios changing some of the variables. A probabilistic sensitivity analysis based on the uncertainty around each parameter was not conducted, which could be considered in future studies.

Although the China National Strategy for COPD Management encourages physicians in China to adopt the GOLD recommendations, evidence of long-acting maintenance therapy use for patients with COPD after hospitalisation for an exacerbation is suboptimal. Through modelling, this study shows that by administering longacting maintenance therapy after hospital discharge, the risk of experiencing more exacerbations, especially exacerbations requiring hospitalisation, could be decreased. The findings of this study provide strong evidence for clinical and policy actions to support the implementation of the national strategy for COPD.

Acknowledgements We would like to thank James Teague, an employee of AstraZeneca, for his role in supporting the project, with no role in the interpretation of the results. Editorial support was provided by Julia King, PhD, of CMC Connect, McCann Health Medical Communications, which was funded by AstraZeneca, Gaithersburg, USA in accordance with Good Publication Practice (GPP3) guidelines.
Contributors $\mathrm{AS}, \mathrm{MR}, \mathrm{ML}, \mathrm{HZ}$ and $\mathrm{HH}$ contributed to the underlying desk research of the current work, the conceptual design, and building of and running the model. All authors took part in the critical appraisal of the model concept, the input data and overall face validity. All authors participated in the interpretation of data reported, drafting and revising of the manuscript, provided final approval of the version to be published and agreed to be accountable for all aspects of the work. All authors have read and approved the final manuscript.

Funding Grant for this study was provided by AstraZeneca. Also, IQVIA, the employer of AS, MR and ML, received consulting fees from AstraZeneca to conceptualise and build the model, collect data and write this manuscript along with the coauthors.

Competing interests $\mathrm{HH}$ has provided professional training to AstraZeneca, outside the submitted work. $\mathrm{HZ}$ is a full-time employee of AstraZeneca. MR and ML are employees of IQVIA, and AS is a former employee of IQVIA.

Patient and public involvement Patients and/or the public were not involved in the design, or conduct, or reporting, or dissemination plans of this research.

Patient consent for publication Not required.

Provenance and peer review Not commissioned; externally peer reviewed.

Data availability statement Data are available upon reasonable request by emailing the corresponding author.

Open access This is an open access article distributed in accordance with the Creative Commons Attribution Non Commercial (CC BY-NC 4.0) license, which permits others to distribute, remix, adapt, build upon this work non-commercially, and license their derivative works on different terms, provided the original work is properly cited, appropriate credit is given, any changes made indicated, and the use is non-commercial. See: http://creativecommons.org/licenses/by-nc/4.0/.

ORCID iD

Hao Hu http://orcid.org/0000-0001-9441-106X

\section{REFERENCES}

1 Global Initiative for Chronic Obstructive Lung Disease. 2019 report: global strategy for the diagnosis, management and prevention of COPD, 2019. Available: https://goldcopd.org

2 Spurzem JR, Rennard SI. Pathogenesis of COPD. Semin Respir Crit Care Med 2005;26:142-53.

3 GBD 2017 Causes of Death Collaborators. Global, regional, and national age-sex-specific mortality for 282 causes of death in 195 countries and territories, 1980-2017: a systematic analysis for the global burden of disease study 2017. Lancet 2018;392:1736-88.

4 Miravitlles M, Ribera A. Understanding the impact of symptoms on the burden of COPD. Respir Res 2017;18:67.

5 Sullivan SD, Ramsey SD, Lee TA. The economic burden of COPD. Chest 2000;117:5S-9.

6 Patel JG, Nagar SP, Dalal AA. Indirect costs in chronic obstructive pulmonary disease: a review of the economic burden on employers and individuals in the United States. Int J Chron Obstruct Pulmon Dis 2014;9:289-300.

7 Bao H, Fang L, Wang L. [Prevalence of chronic obstructive pulmonary disease among community population aged $\geq 40$ in China: a Meta-analysis on studies published between 1990 and 2014]. Zhonghua Liu Xing Bing Xue Za Zhi 2016;37:119-24.

8 Fang L, Gao P, Bao H, et al. Chronic obstructive pulmonary disease in China: a nationwide prevalence study. Lancet Respir Med 2018;6:421-30.

9 Zhou M, Wang $\mathrm{H}$, Zeng $\mathrm{X}$, et al. Mortality, morbidity, and risk factors in China and its provinces, 1990-2017: a systematic analysis for the global burden of disease study 2017. Lancet 2019;394:1145-58.

10 He Q-Y, Zhou X, Xie C-M, et al. [Impact of chronic obstructive pulmonary disease on quality of life and economic burden in Chinese urban areas]. Zhonghua Jie He He Hu Xi Za Zhi 2009;32:253-7.

11 Lou P, Zhu Y, Chen P, et al. Vulnerability of patients with chronic obstructive pulmonary disease according to gender in China. Int $J$ Chron Obstruct Pulmon Dis 2012;7:825.

12 Gao J, Prasad N. Chronic obstructive pulmonary disease in China: the potential role of indacaterol. J Thorac Dis 2013;5:549-58.

13 Zhong N, Wang C, Yao W, et al. Prevalence of chronic obstructive pulmonary disease in China: a large, population-based survey. Am J Respir Crit Care Med 2007;176:753-60.

14 Ding B, Small M, Bergström G, et al. COPD symptom burden: impact on health care resource utilization, and work and activity impairment. Int J Chron Obstruct Pulmon Dis 2017;12:677-89. 
15 China health insurance research association China health insurance database 2015.

16 Zafari Z, Bryan S, Sin DD, et al. A systematic review of health economics simulation models of chronic obstructive pulmonary disease. Value Health 2017;20:152-62.

17 National Bureau of Statistics of China. Chinese statistics yearbook, 2016.

18 Global Initiative for Chronic Obstructive Lung Disease (GOLD). AtA-glance outpatient management reference for chronic obstructive pulmonary disease (COPD), 2017. Available: https://goldcopd.org

19 Antonelli Incalzi R, Fuso L, De Rosa M, et al. Co-morbidity contributes to predict mortality of patients with chronic obstructive pulmonary disease. Eur Respir J 1997;10:2794-800.

20 Tricco AC, Strifler L, Veroniki A-A, et al. Comparative safety and effectiveness of long-acting inhaled agents for treating chronic obstructive pulmonary disease: a systematic review and network meta-analysis. BMJ Open 2015;5:e009183.

21 Wang J, Nie B, Xiong W, et al. Effect of long-acting beta-agonists on the frequency of COPD exacerbations: a meta-analysis. J Clin Pharm Ther 2012;37:204-11.

22 Pavord ID, Jones PW, Burgel P-R, et al. Exacerbations of COPD. Int $J$ Chron Obstruct Pulmon Dis 2016;11:21-30.

23 Müllerova H, Maselli DJ, Locantore N, et al. Hospitalized exacerbations of COPD: risk factors and outcomes in the ECLIPSE cohort. Chest 2015;147:999-1007.

24 Maia IS, Pincelli MP, Leite VF, et al. Long-acting muscarinic antagonists vs. long-acting $\beta 2$ agonists in COPD exacerbations: a systematic review and meta-analysis. J Bras Pneumol 2017:43:302-12.

25 Garcia-Aymerich J, Serra Pons I, Mannino DM, et al. Lung function impairment, COPD hospitalisations and subsequent mortality. Thorax 2011;66:585-90.

26 Almagro P, Calbo E, Ochoa de Echagüen A, et al. Mortality after hospitalization for COPD. Chest 2002;121:1441-8.

27 Miravitlles M, D'Urzo A, Singh D, et al. Pharmacological strategies to reduce exacerbation risk in COPD: a narrative review. Respir Res 2016;17:112.

28 Mills EJ, Druyts E, Ghement I, et al. Pharmacotherapies for chronic obstructive pulmonary disease: a multiple treatment comparison meta-analysis. Clin Epidemiol 2011;3:107-29.

29 Santibáñez M, Garrastazu R, Ruiz-Nuñez M, et al. Predictors of hospitalized exacerbations and mortality in chronic obstructive pulmonary disease. PLoS One 2016;11:e0158727.

30 Soler-Cataluña JJ, Martínez-García MA, Román Sánchez P, et al. Severe acute exacerbations and mortality in patients with chronic obstructive pulmonary disease. Thorax 2005;60:925-31.

31 Hurst JR, Vestbo J, Anzueto A, et al. Susceptibility to exacerbation in chronic obstructive pulmonary disease. $N$ Engl J Med 2010;363:1128-38.

32 Oba Y, Keeney E, Ghatehorde N, et al. Dual combination therapy versus long-acting bronchodilators alone for chronic obstructive pulmonary disease (COPD): a systematic review and network metaanalysis. Cochrane Database Syst Rev 2018;12:CD012620.

33 Calzetta L, Cazzola M, Matera MG, et al. Adding a LAMA to ICS/ LABA therapy: a meta-analysis of triple combination therapy in COPD. Chest 2019;155:758-70.

$34 \mathrm{Au} \mathrm{DH}$, Bryson CL, Chien JW, et al. The effects of smoking cessation on the risk of chronic obstructive pulmonary disease exacerbations. J Gen Intern Med 2009;24:457-63.

35 Miller DK, Homan SM. Determining transition probabilities: confusion and suggestions. Med Decis Making 1994;14:52-8.
36 Singh D, Papi A, Corradi M, et al. Single inhaler triple therapy versus inhaled corticosteroid plus long-acting $\beta_{2}$-agonist therapy for chronic obstructive pulmonary disease (TRILOGY): a double-blind, parallel group, randomised controlled trial. Lancet 2016;388:963-73

37 Chen X, Wang N, Chen Y, et al. Costs of chronic obstructive pulmonary disease in urban areas of China: a cross-sectional study in four cities. Int J Chron Obstruct Pulmon Dis 2016;11:2625-32.

38 Li M, Wang F, Chen R, et al. Factors contributing to hospitalization costs for patients with COPD in China: a retrospective analysis of medical record data. Int J Chron Obstruct Pulmon Dis 2018;13:3349-57.

39 Husereau D, Drummond M, Petrou S, et al. Consolidated health economic evaluation reporting standards (CHEERS)-explanation and elaboration: a report of the ISPOR health economic evaluation publication guidelines good reporting practices task force. Value Health 2013;16:231-50.

40 Yin $\mathrm{P}$, Wang $\mathrm{H}$, Vos $\mathrm{T}$, et al. A subnational analysis of mortality and prevalence of COPD in China from 1990 to 2013: findings from the Global Burden of Disease Study 2013. Chest 2016;150:1269-80.

41 Karabis A, Mocarski M, Eijgelshoven I, et al. Economic evaluation of aclidinium bromide in the management of moderate to severe COPD: an analysis over 5 years. Clinicoecon Outcomes Res 2014;6:175-85.

42 AstraZeneca. Bevespi Aerosphere approved in China for patients with COPD, 2020. Available: https://www.astrazeneca.com/mediacentre/press-releases/2020/bevespi-aerosphere-approved-in-chinafor-patients-with-copd.html/

43 GlaxoSmithKline (GSK). GSK Anoro Ellipta, a new once-daily dual bronchodilators treatment for COPD approved in China, 2018. Available: http://www.gsk-china.com/en-gb/media/press-releases/ 2018/gsk-anoro-ellipta-a-new-once-daily-dual-bronchodilatorstreatment-for-copd-approved-in-china/

44 Sosei Heptares. Sosei Heptares announces that Ultibro® Breezhaler $®$ and Seebri $\circledast$ Breezhaler $®$ launched in China for the treatment of COPD, 2019. Available: https://soseiheptares.com/ news/509/129/osei-Heptares-announces-that-Ultibro-Breezhalerand-Seebri-Breezhaler-launched-in-China-for-the-treatment-ofCOPD.html

45 Sun Z, Wang S, Barnes SR. Understanding congestion in China's medical market: an incentive structure perspective. Health Policy Plan 2016;31:390-403.

46 Ramos M, Haughney J, Henry N, et al. Cost versus utility of aclidinium bromide $400 \mu \mathrm{g}$ plus formoterol fumarate dihydrate $12 \mu \mathrm{g}$ compared to aclidinium bromide $400 \mu \mathrm{g}$ alone in the management of moderate-to-severe COPD. Clinicoecon Outcomes Res 2016;8:445-56.

47 Puhan MA, Gimeno-Santos E, Cates CJ, et al. Pulmonary rehabilitation following exacerbations of chronic obstructive pulmonary disease. Cochrane Database Syst Rev 2016;12:CD005305

48 Vasilopoulou M, Papaioannou Al, Kaltsakas G, et al. Homebased maintenance tele-rehabilitation reduces the risk for acute exacerbations of COPD, hospitalisations and emergency department visits. Eur Respir J 2017;49:1602129.

49 Jones SE, Green SA, Clark AL, et al. Pulmonary rehabilitation following hospitalisation for acute exacerbation of COPD: referrals, uptake and adherence. Thorax 2014;69:181-2.

50 Battisti WP, Wager E, Baltzer L, et al. Good publication practice for communicating company-sponsored medical research: GPP3. Ann Intern Med 2015;163:461-4. 